\title{
Ethics of research with psychiatric patients: principles, problems and the primary responsibilities of researchers
}

\author{
K W M Fulford and K Howse Warneford Hospital, Oxford and St George's Hospital Medical School, London \\ respectively
}

\section{Authors' abstract}

In this paper some of the general issues surrounding recently published guidelines for the practice of research ethics committees are outlined, concentrating in particular on the difficulties raised by research with psychiatric patients. Research is distinguished from ordinary clinical practice by the intention to advance knowledge. So defined, research with psychiatric patients should be governed by the same four principles as research with any other group - knowledge, necessity, benefit and consent. In applying these principles, however, particularly the principle of consent, many acute difficulties are raised by psychiatric patients. $A$ number of proposals for addressing these difficulties are discussed. It is suggested that, notwithstanding the value of published guidelines, and the help that may be available from research ethics committees, the primary responsibility for maintaining high standards of practice in research rests with research workers themselves.

\section{Introduction}

1990 was a good year for research ethics in the United Kingdom. The Royal College of Physicians produced a revised and updated version of its Guidelines on the Practice of Ethical Committees in Research involving Human Subjects (1), together with a companion report, Research involving Patients (2). The Royal College of Psychiatrists prepared a detailed supplement to this document (3). The Department of Health issued their own draft guidelines for comment (4). These documents provide a valuable framework of practical recommendations for all those responsible for medical research involving patients. They leave unresolved, however, a number of issues and difficulties. It is with some of these, especially as raised by psychiatric patients, that this paper is concerned. The common theme that will emerge is the central importance of individual research workers in the development and maintenance of high standards of practice in medical research.

\section{Key words}

Psychiatric ethics; research.

\section{Definition and principles}

Research, whether therapeutic or non-therapeutic, is most usefully defined in relation to ethical questions by its intention to advance knowledge. This definition provides a direct link with the ethics of research. The ethics of ordinary clinical practice are governed by the broadly Hippocratic principle that the patient's interests should normally come first. It is the potential subordination of this principle to the advancement of knowledge that creates the need for ethical principles specific to research.

These principles are the same for psychiatric patients as for any other group. They may be formulated thus:

1. KNOWLEDGE: there should be a reasonable expectation that the research will produce an increase in knowledge that is directly or indirectly relevant to patient care.

2. NECESSITY: there should be no practical possibility that the same increase in knowledge could be achieved other than by working with patients as research subjects.

3. BENEFIT: the potential benefits (to the research subjects or others) arising from the expected increase in knowledge should be of sufficient importance to outweigh any risks of harm inherent in the research.

4. CONSENT: patients should give valid consent to their participation in research; that is, they should assent freely and on the basis of appropriate information.

\section{Difficulties in applying these principles}

Although the principles governing good practice in research are largely uncontentious, difficulties often arise when it comes to applying them in practice. The difficulties may be especially acute in the case of psychiatric patients. Thus:

KNOWLEDGE: The 'corpus' of knowledge is less well established in psychology and the brain sciences than in other disciplines relevant to medicine. Hence it will more often be the case in psychiatry that there is disagreement among experts about the likely 
extent of any increase in knowledge from a given research project.

NECESSITY: Psychopathology, unlike physical pathology, is a predominantly human phenomenon. Also, it is revealed mainly by self-report. Hence there is less scope in psychiatry than in other branches of medicine for using animals in research and thus for avoiding the necessity of working with patients.

BENEFIT: Three main kinds of difficulty may arise in the assessment of the risks and benefits of research with psychiatric patients:

i) Empirical: As already noted, there is rather less in the way of an established corpus of knowledge in psychiatry than in many other branches of medicine. The likely clinical usefulness of a research project and its inherent risks of harm may thus be difficult to assess with any confidence. For example, the difficulties of psychiatric diagnosis can make for uncertainties about the extent to which the results even of drug-treatment trials can be transferred to everyday clinical practice: and in psychotherapy research the very criteria by which outcome should be measured may be at issue (5). It should be added, though, that whatever the difficulties of predicting outcome, most psychiatric research, as against say the more esoteric areas of biochemistry, is at least directly concerned with patients and their difficulties. Thus, while the overall utility of a given psychiatric research project may be at issue, its clinical relevance will generally not be in doubt.

ii) Evaluative: In addition to the empirical difficulties involved in assessing the likely benefits and harms arising from a psychiatric research project, there may be difficulties about what should count as a benefit or harm. These difficulties of evaluation may be of two kinds. They may be non-specific, ie, concerned with judgements simply of good and bad. There may be differences of view, for example, about what should count as a good or bad outcome, a benefit or a harm, in behaviour therapy. The question of what should count as 'desirable' behaviour is raised directly by the need for precise definition of goals in treatment of this kind (6); whereas, as Wing has pointed out, it is commonly neglected altogether in 'social' therapies (7). But evaluative difficulties may also be specific, ie, concerned with the specifically medical judgements of health and disease: is grief, for example, a disease to be 'cured' (8); or, more contentiously, homosexuality (9)? The proper scope of medical research may thus be at issue in psychiatry in ways, or to an extent, that it is not in other areas of medicine.

iii) Conflicts of interest: The risks, as well as the benefits, of research in psychiatry may accrue to individuals other than the actual patient, thus giving rise to conflicts of interest. This is notoriously so in family therapy, for example. Such difficulties, though, are certainly not confined to psychiatric research. For instance, the work required for the development of pre-symptomatic genetic testing for inherited conditions such as Huntington's Chorea, can have highly unwelcome implications for members of the patient's family (10).

CONSENT: Either or both of the elements of valid consent - that it be given freely and on the basis of appropriate information - may be problematic in psychiatric research.

The difficulties involved in establishing that consent is given freely include:

i) Covert pressures: Psychiatric patients are often especially vulnerable emotionally. The difficulties here have been examined empirically, though mainly in respect of treatment rather than research, by Lidz, Meisel et al (11). They found that while active coercion is generally avoided, there is a particular danger of covert (though mostly unintentional) pressures arising from the unequal power relationship between doctor and patient. Certain groups are especially at risk in this respect, for example, involuntary patients and mentally abnormal offenders in prison.

ii) Problems of decision and action: Our capacities for decision and action may be adversely affected by a wide variety of psychological disorders: for example, obsessive-compulsive disorders often involve a generalised inability to make decisions; mood disorders may involve pathological motivations (such as the depressed patient who agrees to take part in a research project in the hope that it will kill him); and in psychotic disorders there may be profound impairments of insight (as with the deluded patient who believes that a research project is really an initiation ceremony offering access to supernatural powers).

The corresponding difficulties in relation to issues raised by the information element in consent include:

i) How much information is appropriate: In ordinary clinical practice full disclosure of all the risks and benefits of a proposed procedure is generally not required for consent to be valid. In the UK, for example, a doctor has to reveal only as much information as would be revealed by any responsible and skilled body of his or her peers (the so-called 'prudent doctor' test). With research procedures, however, there is a strong presumption that more complete disclosure is necessary. It is recognised that full understanding of a research project amounting as it would to a lengthy and to many patients incomprehensible seminar - is generally impractical. Nonetheless, in the Royal College of Physicians' guidelines, adequate information is taken to include 'any benefits and hazards' (12), and where simplification is necessary this should 'not have the effect of understating any risks or glossing over inconvenience or discomfort' (13). Achieving this degree of information, however, as a basis for a 
balanced decision about participation in research, presents many difficulties. These have been widely discussed in relation to the problem of consent to inclusion in randomised trials $(14,15)$. But in some areas of psychiatric and psychological research a degree of active deception is sometimes required (14). Full disclosure even of the purposes of the research can sometimes so alter the subject's responses as to invalidate the results: false feedback experimental designs, for example, are not uncommon in psychological research; and some of these may even involve paradoxical intent, in which the therapist suggests certain responses or courses of action with the intention of provoking their contraries (16).

The standard proposed by the Royal College of Psychiatrists is less comprehensive than that suggested by the Royal College of Physicians (17). After noting that it is not possible to give detailed guidelines covering every case, it suggests that 'important' risks (rather than 'any', as in the Royal College of Physicians' guidelines) should be made clear. What is important is in turn to be defined by reference to an ethics of research committee which should 'apply commonsense to decide what level of risk would be likely to affect a reasonable person's decision'. Further, where incomplete disclosure of information is proposed, the research should not be carried out where it is considered that on a basis of full information, the patients concerned would be expected to withhold their consent.

What this amounts to, then, is a 'reasonable person' rather than, as in ordinary clinical practice, a 'reasonable doctor' test of adequacy of information. However, while providing sound general principles, the reference to commonsense raises many of the difficulties involved in achieving adequate understanding in this context. In psychiatric research patients are by definition, in one or other respect, and to a lesser or greater degree, unreasonable. And as Taylor has emphasised (18), while there are many excellent theoretical discussions of the nature of competence in the literature (19), the common assumption that there will be general agreement in practice over judgements of competence is wholly misplaced. Hence commonsense, which is perhaps an insecure guide even to the soundness of the decisions of normal people, may actually be misleading here.

ii) Problems of understanding: The most obvious difficulties of understanding arise with disorders involving disturbances of cognitive or intellectual functioning (for instance, in mental handicap, dementia and confusional states). However, a wide variety of communication difficulties may be associated with other species of psychopathology. Anxiety, for example, is a barrier to communication of a general kind that may be much increased in a number of mental disorders. Similarly, depression may produce a slowing of intellectual processes that resembles dementia; and in hypomania there may be marked distractibility.

\section{Patients unable to give consent}

The difficulties just outlined may sometimes be so extreme as to invalidate consent altogether. The problem of consent has been most discussed in respect of difficulties arising from the patient's psychopathology - defective comprehension, for example, and severely impaired insight. However, coercion (overt or covert), material non-disclosure, and plain misunderstanding may all invalidate consent.

This raises particular problems for research. In relation to ordinary clinical practice, the ethics of involuntary psychiatric treatment (although certainly contentious) can be derived from the Hippocratic principle. Involuntary treatment of a patient whose capacity for consent is impaired may be justified under the Hippocratic principle if it is either in that patient's interests or (a widely recognised although still contentious exception) necessary for the protection of others from serious harm (20). A research procedure, on the other hand, defined by the intention to advance knowledge, must be differently justified. Any benefits to the patient, direct or indirect, are (by the definition of research itself) secondary; and the principle of protecting others from harm is essentially a restrictive principle, the purpose of which is precisely to limit to exceptional cases any subordination of the patient's interests.

It is because the patient's interests are subordinate in this way that the ethical requirements for consent to a research procedure are more rigorous than those for consent to treatment. With a research procedure it is the patient's assent, not merely the absence of their dissent, that must normally be considered valid, and this of course greatly extends the number of potentially problematic cases. The Mental Health Act 1983 and its companion volume, The Code of Practice (21), are both silent on the question of research. The Royal College of Psychiatrists' guidelines suggest that dissenting patients should always be excluded from research, whether or not they are considered competent (22). Even this restriction could raise difficulties - for example, in studies of involuntary admissions or treatment procedures under the Mental Health Act. However, the point is that in research, all incompetent patients, even those assenting, are ethically problematic. Furthermore, there is a medico-legal twist to the problem. For, at least under English law, the consent of a third party (of a relative, say) is legally effective only in the case of children. Hence, while involuntary psychiatric treatment is covered by the Mental Health Act, there is at least a possibility that research procedures with adult incompetent patients (whether assenting or not) may actually be illegal. Indeed, where such research involves touching (for example to take a 
sample of blood) it could conceivably result in an action in battery (23).

It is important to keep these problems in perspective. In the first place, on the question of battery, legal opinion itself is divided (24). Then again, as the Royal College of Psychiatrists' guidelines emphasise (25), much psychiatric research can be carried out with patients whose capacity for consent is unimpaired. The capacity for consent, furthermore, is not all-or-nothing. Hence, even with severely incapacitated patients it may still be possible to obtain valid consent if sufficient care is taken in overcoming the difficulties (see below).

It is also important to be aware that even when patients really are incapable of meaningful consent, the ethics of research are not all one way. Proceeding without consent is certainly ethically hazardous. But if a potentially important advance in medical knowledge is at stake, and if, further, the risks of harm are minimal, it could well be unethical not to proceed. There are possible parallels here with the case of children who have not reached a stage of maturity at which they are able to give meaningful consent. Adult patients should not be treated as children, especially if they are severely incapacitated; this (which happens all too frequently even in ordinary clinical care) would be an affront to the dignity of the person concerned. But similar balancing considerations lie behind the justification of research in the two kinds of case: the balancing of responsibilities against rights, of longer term benefits against immediate wishes, of the needs of society against those of the individual. Provided, therefore, a humane and sensitive approach is adopted, and that the agreement of close relatives and other caregivers is obtained, research at least with assenting adult incompetent patients is unlikely to be regarded as unethical.

On the other hand, though, it is important that the problems are not underestimated. There is a tendency in published guidelines to play down the difficulties raised by research with incompetent patients, to suggest that they are merely theoretical, or apply only to small numbers and exceptional cases. The Royal College of Psychiatrists' guidelines, for example, while emphasising the importance of the ethical problems raised by incompetent patients, suggest that this 'group is small' since 'to suffer from severe dementia or mental handicap does not necessarily imply incompetence; and incompetence to make one kind of decision does not necessarily mean incompetence to make another kind' (25).

Yet this is too anodyne, surely. Even 'mild' dementia (as defined, say, by the 'mini-mental state' examination) (26) may involve failures in such elementary cognitive tasks as remembering a list of three household objects (for example, comb, table, flower) after two minutes, or reciting the months of the year backwards. So that by any 'commonsense' standards (to which, as described above, the assessment of risk is referred by the Royal College of Psychiatrists' guidelines) such patients, let alone those with severe dementia, can hardly be considered competent to make complex decisions about participation in research.

As already stated, it is important that the problems in this area are not exaggerated. This is important, if for no other reason than exaggeration could inhibit research with precisely those patients those most severely incapacitated - who are in greatest need. But denial may not be the best way to facilitate research. It could lead to unsatisfactory (because ill-founded) consideration of the ethical problems in this area, and hence to an increased rather than decreased risk of unethical research practice. Similarly, the fear of litigation is bound to persist so long as the present uncertain state of the law is allowed to continue. This fear, furthermore, is one to which not only researchers, but also the members of research ethics committees are subject, given the responsibilities of the latter in law (Royal College of Psychiatrists' guidelines (27). That the fear of litigation is to some extent justified, is shown by the fact that some commentators, notably those representing organisations concerned to protect patients' rights, have sought to proscribe certain groups from research altogether. MIND, for example, took this position in its evidence to the Royal College of Physicians' Working Party on Research involving Patients.

\section{Proscribed patients}

As a response to the problems raised by research with incompetent adult patients, proscription may be variously motivated. It may be strategic, a group identified as particularly vulnerable being proscribed with the intention of setting a clear limit to what is perceived as the legitimate scope of research. Proscription, again, may be precautionary: from a medico-legal point of view, for example, it is no more than prudent to avoid research with dissenting patients wherever possible.

As a specifically ethical response to the difficulties, however, proscription is less readily justified. Patients have a right to decline to take part in research, and proscription recognises the need to protect those who may not be capable of exercising that right. But as the Royal College of Psychiatrists' guidelines indicate (28), there are countervailing rights: a right to the best treatment; and a right to take part in research and thus to contribute to establishing which treatments are best. These latter rights, furthermore, correspond with the responsibilities of doctors and other health-care workers to improve our knowledge of the risks and benefits of medical treatments. The principle of necessity, as a principle of distributive justice, must always be satisfied. It must always be the case that a given research project cannot be done with a less vulnerable group. This 
principle alone will ensure that, say, dissenting patients are rarely if ever involved in research. But such patients should not be proscribed as such. There will always be a balance of considerations; of risks with benefits, for the patient and others; of rights with rights; and of rights with responsibilities.

\section{A balance model of ethical reasoning}

Proscription represents an extreme case of the desire for certainty in ethical decision-making, for rules that can be used as a substitute for ethical reasoning. It is part of the argument of this paper that ethical guidelines in general should not be used in this way. As against this, however, the very variety of considerations that have to be weighed in a balance 'model' of ethical reasoning, places a considerable extra demand on those carrying out research.

A properly constituted research ethics committee can be helpful here. Indeed, in respect of the first three guiding principles in particular (knowledge, necessity and benefit), referral to a research ethics committee is an essential procedural safeguard. But the special contribution of such a committee is derived from the variety of opinion that it represents. In respect of empirical considerations, although not constituted as a scientific review body, it may include (or where appropriate can co-opt) relevant experts. Equally important, though, as a counterbalance to the enthusiasms of experts, are the opinions of lay members. This is true of empirical considerations. It is true to an even greater extent of evaluative considerations. Precisely because such a committee is not constituted as a scientific review body, it can draw on a range of points of view in coming to balanced conclusions on questions of value.

It is here, though, that we begin to see the central role of researchers themselves. If good standards of practice in research could be secured simply by reference to a set of rules or a check-list, then procedural safeguards would be sufficient. But if a balanced view is to be achieved across a variety of opinion, in particular lay or non-specialist opinion, then responsibility for providing clear and relevant information about a proposed research project rests firmly with the researcher. Most research proposals are subject to scientific peer review and, as already noted, there may be differences of opinion between experts, especially in relation to certain areas of psychiatric research. This makes it all the more important, however, that in submitting a research proposal to an ethics of research committee, researchers provide clear non-technical information on all matters relevant to the ethical aspects of their work.

This will clearly be so in relation to the first three guiding principles - the likely increase in knowledge, the necessity for working with the group of patients proposed, and the balance of benefits and harms.
But the point is made especially strongly in respect of the fourth principle, that of consent. Thus:

i) Covert coercion: Various proposals have been made for protecting the patient from covert coercion: that consent be requested by a third party (for example, a nurse or doctor not involved in the research); that a relative, or even a 'befriender' or 'advocate', be present; that consent be requested in the patient's home or some other informal environment. Each of these proposals may be helpful in certain circumstances. However, the patient and researcher must eventually come face to face, if not at the outset, then during the course of the research. This is because consent should not be just a one-off event but an on-going state, with the patient retaining the ability to withdraw at any stage. Hence, responsibility for avoiding undue pressures inevitably comes back in the end to the researcher.

ii) Disclosure of information: As described above, even though the standards for disclosure of information are higher for research than for ordinary clinical practice, it remains the case that full disclosure is rarely practical. Hence a view must always be taken about how much information is necessary for consent to be valid in a given case. There are various ways in which this might be achieved. An ethics of research committee will always be involved, however, and the committee will be dependent on the information supplied to it by the researcher, as already described.

iii) Difficulties arising from specific psychopathologies: The researcher, through his or her specialised knowledge, is likely to be the best person to deal with any difficulties of valid consent arising from the patient's psychopathology. Many of the difficulties of decision and action, especially those related to severely impaired insight, are poorly understood, and there is often little that can be done about them (but see below). Communication difficulties, however, are rather well understood. It is reasonable therefore to expect that the experimental design should include proposals covering both general communication skills (use of appropriate language, repetition, sufficient time for questions and answers, written material for the patient to keep, etc), and also the means for dealing with difficulties arising from particular psychopathologies. The importance of this is not only ethical but also heuristic, since the way in which a patient understands the nature of a research procedure may materially affect the results obtained.

\section{Other considerations}

Important as it is, there is more to the development of good practice in research than a sound 'model' of ethical reasoning. First, there is a need for education. Many medical schools are now providing training in medical ethics and law and in the 
communication skills that are essential to good practice. These subjects are as important in research as in ordinary clinical care. Then again, there is a need for vehicles for the accumulation of shared experience. The royal colleges could provide this; or perhaps a national research ethics committee, or even an association established on voluntary lines.

Above all, though, there is a need for research practice itself to become a subject of research. It will be clear from what has been said in this paper, that if standards of practice in research are to improve, research on research is needed in a number of areas:

i) empirical: Covering communication skills, what is helpful and what is not, in general and with specific psychopathologies;

ii) ethical: For example, examining what patients, relatives, nurses and other clinical caregivers, actually feel about research. It is generally assumed that research is an imposition. But it can have beneficial effects on outcome $(29,30)$. Moreover, patients may actually welcome the opportunity to take part in research, and thus to help others with problems similar to their own.

iii) conceptual: Directed especially towards clarifying the concepts of health and disease. One reason for the difficulties raised by incompetent patients is that the connections (ie, the conceptual connections) between psychopathology and rationality are so poorly understood $(20,31)$ (this is especially so for impairment of insight, as in deluded patients). Conceptual analysis may also contribute to improved communication generally, for example by making explicit and clarifying cultural differences in the conceptualisation of health and disease.

iv) medico-legal: The problem of the legal ineffectiveness of proxy consent with adult patients has only recently begun to be considered in the United Kingdom in connection with treatment, and in connection with research it has received hardly any attention at all. There is a view that the law in this area should be allowed to develop case-by-case. But the insecurities this will engender have already been outlined. Case law, furthermore, is no guarantee that appropriate legal principles will become established: the emphasis, for example, on the patient's best interests in the judgement in the recent case of ' $F$ ' (32), underlines the potential divide in this area between the requirements respectively of research and ordinary clinical care.

Research budgets are of course severely limited. With the help of researchers themselves, however, research on research need not be expensive. Thus, while there is a need for direct funding of research on research, much useful work could be piggy-backed on other projects. For example, one or two additional questions could be included in a questionnaire, covering how the patient felt about being asked to participate in the research, whether the experience was as he or she had been led to expect, and so on. 'Market research' of this kind could provide an invaluable guide to the development of future projects. More ambitious work along the same lines could be attempted by including additional disciplines (a philosopher, or a medical anthropologist, say) in a research team. Similarly, with a minimum of additional administration, research ethics committees could monitor the outcome of at least a proportion of their decisions. It is well recognised that there is considerable variation in the way these committees operate (33), and a small additional effort to assess their effectiveness would seem worthwhile.

Each of these proposals would involve researchers in a certain amount of additional work. But to balance this, on the profit side as it were, the returns from research on research could be considerable. Such research would address public concerns, reduce rates of refusal and 'drop out', and improve the quality of research itself. As in other areas, then, the ethical requirements of good practice, far from being an impediment, are entirely compatible with and support the proper objectives of research with patients.

\section{Conclusions}

Although sometimes perceived as a barrier to research, a properly functioning ethics of research committee can provide valuable guidance and support in the development of research proposals involving patients. Recently published guidelines should contribute to this process by establishing principles of good practice broadly acceptable to everyone involved in research, not least patients themselves and their relatives. Nonetheless the primary responsibility for good practice in research comes back at a number of points to those actually carrying out the research.

\section{Acknowledgements}

The authors are grateful to Professor M G Gelder, Dr A R Hope, Mrs J Robinson and Mrs E Snow for their most helpful comments on an early version of this paper.

KWM Fulford, MA, DPhil, is Research Fellow, Green College, Oxford University. K Howse, MPhil, is Research Fellow in the Division of Addictive Behaviour, St George's Hospital Medical School, London.

\section{References}

(1) The Royal College of Physicians. Guidelines on the practice of ethical committees in research involving human subjects (2nd ed). London: The Royal College of Physicians of London, 1990.

(2) The Royal College of Physicians. Research involving patients. London: The Royal College of Physicians of London, 1990. 
(3) The Royal College of Psychiatrists. Guidelines for research ethics committees on psychiatric research involving human subjects. Psychiatric bulletin 1990; 14:48-61.

(4) Department of Health. Local research ethics committees. London: HMSO, 1991.

(5) Farrell B A. The standing of psycho-analysis. Oxford: Oxford University Press, 1981.

(6) Royal College of Psychiatrists, Royal College of Nursing and British Psychological Society. Ethical guidelines for the conduct of behaviour modification. $\mathrm{O} \mathrm{L}$ Zangwill, chairman. London, HMSO, 1980.

(7) Wing J K. Ethics in psychiatric research. In: Block S, Chodoff P, eds. Psychiatric ethics (2nd ed). Oxford: Oxford University Press, 1991.

(8) Brown J T, Stoudemire A. Normal and pathological grief. Fournal of the American Medical Association 1983; 250: 3; 378-382.

(9) Marmour J. Homosexuality and cultural view systems. American journal of psychiatry 1973; 130: 1208-1209.

(10) Brandt J. Ethical considerations in genetic testing, with examples from presymptomatic diagnosis of Huntington's Disease. In: Fulford K W M, Gillett G, Soskice J, eds. Medicine and moral reasoning. Cambridge: Cambridge University Press (in press).

(11) Lidz C W, Meisel A, Zerubavel E, Carter M, Sestak R M, Roth L H. Informed consent: a study of decisionmaking in psychiatry. New York and London: The Guildford Press, 1984.

(12) See reference (1): para 7.8.

(13) See reference (1): para 7.13.

(14) Brahams D. Randomised trials and informed consent. Lancet 1988; i:1033-1034.

(15) Alderson P. Trust in informed consent. IME bulletin 1988; Jul: 17-19.

(16) Holmes J, Lindley R. The values of psycho-therapy. Oxford: Oxford University Press, 1989.

(17) See reference (2): 49-50.
(18) Taylor P J. Consent, competency and ECT: a psychiatrist's view. Fournal of medical ethics 1983; 9: 146151.

(19) Beauchamp T L, Childress J F. Principles of biomedical ethics (3rd ed). New York: Oxford University Press, 1989.

(20) Fulford K W M. Moral theory and moral practice. Cambridge: Cambridge University Press, 1989.

(21) Department of Health and Welsh Office. Code of practice: Mental Health Act, 1983. London: HMSO, 1990.

(22) See reference (2): 51

(23) Sullivan D. The incapable patient and the law. In: Hirsch S R, Harris J. Consent and the incompetent patient: ethics, law and medicine. London: The Royal College of Psychiatrists, 1988.

(24) See reference (23): Chapter 2. Brooke H. Consent to treatment or research: the incapable patient.

(25) See reference (2): 50

(26) Folstein M F, Folstein S E, McHugh P R. Minimental state. A practical method for grading the cognitive state of patients for the clinician. Fourmal of psychiatric research 1975; 12: 189-198.

(27) See reference (2): 52.

(28) See reference (2): 48

(29) Carroll R S, Miller A, Ross B, Simpson G M. Research as an impetus to improved treatment. Archives of general psychiatry 1980; 37: 377-380.

(30) Ben-Arie O, Koch A, Welman M, Teggin A F. The effect of research on readmission to a psychiatric hospital. British journal of psychiatry 1990; 156: 37-39.

(31) Lesser H. Consent, competency and ECT: a philosopher's comment. Fournal of medical ethics 1983; 9: 144-145.

(32) Brahams D. Sterilization of mentally incapable women. Lancet 1992; i: 1275.

(33) Gilbert C, Fulford K W M, Parker C. Diversity in the practice of district ethics committees. British medical journal 1989; 299:1437-1439. 